\title{
A Economia de Francisco e Clara para "realmar” a humanidade
}

\author{
EDUARDO BRASILEIRO ${ }^{1}$ \\ RUdÁ RICCI ${ }^{2}$
}

Resumo: A proposta do Papa Francisco abre um espaço de discussão na sociedade contemporânea com a Economia de Francisco e Clara. O Papa Francisco convidou jovens de todo o mundo para discutir os rumos da economia mundial, em um convite para "realmar" a economia. O encontro que ocorrerá em Assis abrirá um enorme flanco de discussões em torno de desenvolvimento, capitalismo, extrativismo, passando para o debate central de transição gestado na encíclica Laudato Si'. As etapas que compõem a discussão desenvolvem um olhar sobre o enfrentamento à financeirização da economia global, seu aspecto de dominação da subjetividade humana e, com isso, sua desumanização, centrando esforços em uma nova cultura proposta pelo Pacto Educativo Global. Palavras-chave: Papa Francisco. Economia. Educação. Laudato Si'. Juventudes. Igreja Católica.

\section{Francisco and Clara's Economy to "re-animate" humanity}

Abstract: Pope Francis' proposal opens up a huge space for discussion in contemporary society with The Economy of Francesco and Clara. Pope Francis has invited young people from all over the world to discuss the direction of the world economy, in an invitation called to "re-animate" the economy. The meeting, which will take place in Assisi, will open a huge range of discussions around development, capitalism, extractivism, moving on to the central transition debate in the encyclical Laudato Si'. The stages that make up the discussion develop a look at the financialization of the global economy, its aspect of domination of human subjectivity and with that, its dehumanization, focusing efforts on a new culture proposed by the Global Compact on Education.

Keywords: Pope Francis. Economy. Education. Laudato Si'. Youth. Catholic Church.

\section{La economía de Francisco y Clara para "realmar" la humanidad}

Resumen: La propuesta del Papa Francisco abre un espacio de discusión en la sociedad contemporánea con la Economía de Francisco y Clara. El Papa Francisco invitó jóvenes de todo el mundo a discutir la dirección de la economía mundial, en una invitación llamada a "realmar" la economía. La reunión, que tendrá lugar en Asís, abrirá un enorme flanco de discusiones sobre desarrollo, capitalismo, extracción, pasando al debate central 
de transición generado en la encíclica Laudato Si. Las etapas que conforman la discusión desarrollan una visión sobre cómo enfrentar la financiarización de la economía global, su aspecto de dominación de la subjetividad humana y, con eso, su deshumanización, enfocando los esfuerzos en una nueva cultura propuesta por el Pacto Educativo Global. Palabras clave: Papa Francisco. Economía. Educación. Laudato Si'. Juventud. Iglesia Católica.

\section{Por que uma Economia de Francisco e Clara?}

"De modo geral, para os povos, a narrativa deles do universo e o papel humano no universo é a sua fonte primordial de inteligibilidade e valor. As crises mais profundas vivenciadas por qualquer sociedade são os momentos de mudança quando a narrativa se torna inadequada para enfrentar as exigências de sobrevivência de uma situação que se apresenta".

Thomas Berry (padre e ecoteólogo)

"Que a nossa época seja lembrada como o despertar de uma nova reverência pela vida". A carta da Terra

O Papa Francisco, em seu sétimo ano de pontificado, estabelece os marcos mais duradouros de seu serviço para a sociedade global e apresenta os dois últimos filhos da Encíclica Laudato Si: o encontro global "Economia de Francisco" e o "Pacto Educativo Global" - o filho nascido antes, a saber, foi o Sínodo para a Amazônia.

Ambas as iniciativas trazem no bojo a abertura de processos revolucionários, pois incidem em "[...] ocupar-se mais com iniciar processos do que possuir espaços. O tempo ordena os espaços, ilumina-os e transforma-os em elos de uma cadeia em constante crescimento, sem marcha atrás" (FRANCISCO, 2013c, n. 223). O Papa Francisco assume o compromisso de uma transição global: encaminhar processos que gestem uma sociedade biocêntrica, em que o centro está na vida que supera a economia neoliberal atualmente financeirizada, e passar para aquilo que a delegação brasileira enunciou em sua carta aberta para o Papa e todos os jovens que estarão em Assis:

Economias no plural. Economias solidárias e populares, criativas, colaborativas. A economia circular e ecológica. As economias da dádiva, a festa comunitária, a comunhão. A economia feminista, das mulheres. As economias camponesas e tradicionais. A economia do cuidado, a economia doméstica. As economias digitais e do software livre. A economia da cultura. O mundo do trabalho, enfim. As economias vivas (ARTICULAÇÃO BRASILEIRA PELA ECONOMIA DE FRANCISCO E CLARA, 2019, s/p). 
O Papa Francisco (2019b, s/p) convoca um "realmar" a economia: "que faz viver e não mata, inclui e não exclui”. O foco dessa proposta está na superação das desigualdades globais e, portanto, mexe no coração do atual pacto econômico global: a acumulação sem nenhum precedente na história de uma minoria ilegítima e uma miséria alastrada em todo os territórios do mundo. Afinal, a perversidade do capitalismo está na desregulação das fortunas globais que passeiam por todos os países explorando os Estados-nação, cada um sofrendo pressão de elites locais e internacionais para "flexibilização" a favor de seus interesses.

Portanto, o Papa Francisco convoca um movimento nas proximidades da espiritualidade dos Santos de Assis, São Francisco e Santa Clara, que costuraram uma radical nova forma de viver, para romper um processo engendrado não somente na sociedade, mas na subjetividade de cada sujeito, como afirmaram Dardot e Laval (2016), detalhando o homem e a mulher empresarial. O conflito a que se propõe o Papa Francisco, unido a jovens ativistas, empreendedores sociais e intelectuais engajados, é a humanização da economia. Não se trata, portanto, de uma medida reformista, mas um desencadeamento de um movimento social para este século.

Joseph Stiglitz, fundador do Novo Pensamento Econômico, entidade que animou o Papa a construir essa frente internacional de discussão sobre novos modelos econômicos, afirmou:

É fundamental trabalhar a partir da educação em sistemas alternativos que não tenham como premissa a ideia de idolatrar o dinheiro. Temos que buscar desenvolver programas e estudos em torno do conceito de economia circular, que contribuam para uma educação consciente da sustentabilidade ambiental, que requer devolver ao meio ambiente o que lhe é retirado (LA VANGUARDIA, 2019, s/p).

O Papa Francisco, compreendendo esses desafios, sentenciou que "não há duas crises separadas: uma ambiental e outra social; mas uma única e complexa crise socioambiental" (FRANCISCO, 2015b, n. 139). O capitalismo neoliberal, síntese de tantos nomes que se deram às suas metamorfoses atuais (financeiro, imaterial, parasitário, global), converge seu domínio na "tecnociência" (FRANCISCO, 2015b, n. 107), que suspende o governo do cidadão sobre si e restringe a uma minoria de corporações bélicas.

O exemplo está nos extermínios populacionais e naturais no mundo e o monopólio de tecnologias. As políticas internacionais foram ofertadas a "uma concepção mágica do mercado" (FRANCISCO, 2015b, n. 190), centradas em um descontrole político e econômico de seus interesses, erguendo um monopólio político brutal. 


\section{"Realmar" a economia por meio de novas arquiteturas}

Reivindicar uma nova arquitetura econômica é tarefa de primeira ordem para uma transição social e cultural. O poder de pensar na gestão da escola, de seu bairro, nas decisões do seu município e de grupos culturais, por exemplo, desenha-se como algo intangível em uma democracia de baixa intensidade. O sociólogo e economista alemão Wolfgan Streeck (2012) afirma que vivemos no fim do capitalismo democrático. Esse dado se intensifica com a dificuldade política em ser norteada por princípios como o bem comum a longo prazo, capturando o projeto de nação (FRANCISCO, 2015b, n. 178).

Neste cenário de pandemia do SARS-CoV2 (Covid-19), mostrou-se eminente a falácia da doutrina de austeridade que levou o mundo globalizado a desmontar políticas sociais e econômicas de apoio ao povo, garantindo liberdade econômica a um punhado de corporações que compuseram uma nova elite política econômica. Caberá em um processo de transição, nas palavras de Jurgen Schuldt (apud ACOSTA, 2015, p. 164), a "dissociação seletiva e temporal do mercado mundial", retomando a soberania alimentar, processos de gestão democrática local e popularização do binômio formação de redes comunitárias e ocupação de espaços representativos deliberativos.

Realmar a economia está em superar o modelo de desenvolvimento, reconhecendo que o problema é de organização da vida econômica e, portanto, estabelecer a economia de suficiência, em que Francisco e Clara de Assis e os povos amazônicos e andinos têm muito a nos ensinar, freando a lógica de eficiência que se desdobra na acumulação global materialista. Nas palavras do equatoriano Alberto Acosta (2015, p. 185), presidente de Assembleia Constituinte que reconheceu no Equador os direitos da mãe terra, é:

[...] crer no autocentramento como desenvolvimento das forças produtivas endógenas, incluindo recursos produtivos locais e os correspondentes controle da acumulação e centramento dos padrões de consumo. Tudo deve ser acompanhado de um processo político de participação plena, de tal maneira que se construam contrapoderes com crescente níveis de influência no âmbito local.

Para economistas ortodoxos, é importante ressaltar que não se trata de "substituições de importações", e sim uma essência se destaca: um mercado interno que capacita o viver com o nosso e para os nossos.

A emergência sanitária vivida em 2020 desnuda o fato de que, quando há vontade política, é possível se reverter o processo de globalização. A crise civilizatória e sistêmica revela o último véu de hipocrisia do que muitos analistas chamam de "ordem liberal", ou de "hegemonia americana" do século XX. Urge "realmar" a organização popular que no aspecto político está por repensar profundamente 
em um processo autodependente e participativo, criando fundamentos para uma ordem que concilia economias solidárias e sociedades democráticas.

Nenhuma teoria econômica será sustentável se não respeitar os limites do ecossistema nem será popular se não houver um envolvimento cada vez maior de forças territoriais com processos de autonomia produtiva e cultural. Trata-se aqui de uma ressignificação estrutural dada a magnitude do destino da humanidade e da vida. Com a pandemia, o que ficou evidente não é a autoimplosão do sistema produtivo, mas sua capacidade de reinvenção cruel. Portanto, medidas que recomponham o ser humano ao metabolismo da natureza, retomando a mística franciscana do cuidado, acolhida e diálogo, ganham com o chamado do Papa Francisco a capacidade de "dizer os limites a que a humanidade chegou" e recompor a trama de harmonia com o "sistema vida".

\section{A Economia de Francisco e Clara organiza uma nova cultura e um novo cidadão}

\section{A convivência na multipolaridade}

A proposta do Papa Francisco não se sustenta em um programa único de superação do sistema capitalista. Bebe da fonte de diversos rios que desenharam resistências, reflexões e proposições diante da necessidade de transição do mundo atual. O bem viver dos indígenas, o decrescimento dos europeus, o ubuntu na África, as ecovilas que refletem o desenvolvimento local, tudo são desenhos de arquiteturas possíveis, que não se anulam, e sim se complementam.

As dimensões no entorno do encontro que ocorrerá em Assis com o Papa Francisco e jovens de mundo inteiro foram desenhadas em uma cidade simples, mas carregada de um sentido místico. É o envolver de tradições de fé, de reflexões políticas, sociais e econômicas, na convergência de um projeto comum, que é a superação de dois males centrais do capitalismo neoliberal: a anulação da liberdade e a anulação das potências da vida humana em sua totalidade.

A mística que envolve as tramas das vilas será permeada pela cultura do encontro de:

a) gestão e presente: foco em abordagens para a gestão sustentável;

b) finanças e humanidades: desafios do capitalismo financeirizado por meio de novas formas de partilha e do compromisso em remanejar as grandes fortunas globais para a superação das misérias;

c) trabalho e cuidado: pensar no trabalho na era da revolução 4.0, incidindo pela visão da "Ecologia Integral" (FRANCISCO, 2015b, n. 156), que almeja a superação da lógica de competição e acumulação, remete ao equilíbrio da vida e do trabalho, longe da cadeia de exploração e escravidão em que vivem boa parte das pessoas no mundo; 
d) energia e pobreza: "realmar" a economia com novo sistema energético que vise às capacidades locais de geração de riqueza, saindo do monopólio corporativo;

e) agricultura e justiça: somente com a reforma agrária se prepondera um rompimento com a cadeia produtiva global, concretamente olhando a soberania alimentar.

f) negócios e paz: costurar possibilidades da responsabilidade das grandes corporações nos conflitos regionais pelo planeta e sua superação pela lógica de economias que visem a negócios a partir da cultura colaborativa não extrativista;

g) mulheres para a economia: só ocorrerá uma transição quando as vozes silenciadas, sobretudo as mulheres, envolverem um novo processo econômico; h) CO2 da desigualdade: superar o desequilíbrio da visão única de progressos sustentada em desmatamento e destruição de territórios e pessoas; i) lucro e vocação: entendendo a necessidade de superação dessa lógica atual do capital acima do trabalho, enfocando um desenvolvimento de uma superação do sujeito empresarial (DARDOT; LAVAL, 2016, p. 133), revisitando toda a sua cadeia subjetiva para seres humanos a caminho da liberdade;

j) negócios em transição: para uma relação que privilegie as potencialidades e descobertas humanas e irrompa a cooperação e o compartilhamento no lugar da competição e acumulação;

k) vida e estilo de vida: compreende o desafio de uma nova cultura diante do esmagamento do consumismo e da cultura do bem-estar que cria uma lógica de ganância, afastando-se da economia para o suficiente;

1) políticas para a felicidade: propor uma nova arquitetura das relações humanas, em que a felicidade esteja acima da moral do capital, emergindo necessidades e desejos voltados para as comunidades e cidades inteligentes.

\section{A complementaridade para novas economias}

No Médio Xingu, em Altamira, no Pará, comunidades indígenas viram passar uma necropolítica por meio da imposição das ideias de progresso e soberania (MBEMBE, 2018). Essas ideias que motivaram o capitalismo moderno são filhas do produtivismo e do extrativismo, muito anterior ao capitalismo, que impôs uma lógica sempre crescente de uma ecologia política em torno da relação de dominação do homem com o planeta ao redor. O paradigma emergente, conforme Boaventura Sousa Santos (2010), ou o paradigma da complexidade, de acordo com Edgard Morin (2000), apontam para o que Bruno Latour (2019) afirmou: que fazer ecologia política está na constituição "moderna" de um ser humano desprovido de qualquer poder, mas que compreende a totalidade da 
“criação" (FRANCISCO, 2015b, n. 6), "superando a mentira da dignidade exclusiva da natureza humana” (LÉVI-STRAUSS, 2013, p. 53).

Os exemplos são inúmeros, pois a amarra central de novas narrativas econômicas está nas políticas de guerra perpetradas pelo Estado, em parceria com corporações para a lógica da ganância e lucro capitalista. O desenvolvimento de forças complementares muda de lugar os sujeitos, que passam a compreender a necessidade de pauta unificadas. Portanto, para novas economias, o Xingu é na periferia urbana, e a periferia urbana é no Xingu. Essa narrativa de discussão do poder e sua centralidade na superação de um modelo econômico de morte necessita pulsar aquilo que o sociólogo Otavio Ianni (1997) afirmou: a política mudou de lugar. A economia capturada pelo mercado e a democracia pela necropolítica apresentam os desafios de retomar uma economia política distante das discussões acadêmicas que suscitem nos currículos formativos de economistas e áreas correlatas a compreensão de uma ciência a favor de um novo paradigma.

Novos currículos de economias partem do despossuir a lógica de dominação para construir uma lógica de complementaridade, ou, mais popularmente falando, de unidade na diversidade, compondo uma das sendas de um novo pacto econômico. Está forjado antes das academias nas narrativas de movimentos populares que incidem em uma descolonização dos saberes (DILGER; LANG; PEREIRA FILHO, 2016) por movimentos insurgentes que renovam a teoria crítica, tecendo pensamentos e práticas que reinventem a emancipação socioeconômica. É o que se vê quando são desafiados os movimentos populares e as novas gerações de direitos humanos erigidas nesta última década, ao comporem uma agenda global, sem deslocar-se das necessidades locais, percebendo as identidades em complementaridade aos desafios estruturantes.

\section{A educação no caminho da cidadania ativa}

"O trabalho não é divino; divino são os homens". Thomas Mann

O que a educação tem a ver com a formação para a cidadania? Onde estaria a intersecção entre educar e repensar a economia necessária, a Economia de Francisco e Clara?

Comecemos pela tarefa central dos processos educativos.

Há quem tenha sugerido que a educação tem por finalidade socializar ou introduzir os educandos no mundo dos adultos, das regras e códigos estabelecidos. Essa é a proposta que encontramos em Émile Durkheim (1975), que chegou a sugerir que a pessoa jovem deveria aderir aos valores vigentes por vontade própria, por meio da educação. Na prática, um dos trabalhos vitais do educador seria a de motivar a "submissão consentida" do educando, criando um caminho 
do egocentrismo à vida social. Uma variação dessa sugestão pedagógica seria a instrução para os testes de acesso aos níveis superiores da carreira educacional ou mesmo à inserção no mercado de trabalho a partir de um padrão técnico e de conduta preestabelecidos. Essa intenção fomentou a introdução de preocupações norte-americanas com o comportamento dos educandos (caso das sugestões de John Franklin Bobbitt) ou a adoção de pré-requisitos curriculares, em que um nível básico deveria organizar a base para o educando atingir o nível seguinte (sugestão de Joseph Mayer Rice e dos educadores tayloristas, com base no padrão de educando-trabalhador idealizado para a indústria) ou ainda na produção de testes avaliativos para medir a distância entre o desenvolvimento real dos educandos em relação ao padrão idealizado - caso das reformas educacionais norte-americanas do final do século XX, que, mais tarde, foram duramente questionadas por uma de suas formuladoras, a educadora Diane Ravitch (2011).

A educação para a cidadania não se pauta por padrões predefinidos, mas pela construção de autonomia, a qual, ao contrário da noção de liberdade individual absoluta, é uma construção consciente do educando sobre seu papel na sociedade. Paulo Freire (1996) sugeria que essa construção se dava por meio de um processo que denominava admiração: uma visada sobre suas próprias escolhas, uma autorreflexão sobre seus valores e sua relação com os outros; uma tomada de consciência sobre si e sobre o seu lugar no mundo.

Hannah Arendt (2010) contribuiu para essa vertente pedagógica ao sugerir que não nascemos humanos, mas nos tornamos humanos pela educação. A frase sugere que humanos se inserem na humanidade pelo envolvimento com a experiência coletiva acumulada ao longo do tempo. Pode parecer algo similar ao que sugeria Durkheim, mas é mais profundo. Arendt está se reportando à memória elástica da humanidade; memória que se alimenta da experiência humana repassada pela linguagem, pelas artes plásticas, pela música, pelo teatro, pela escrita. É por esse motivo que nos identificamos com experiências de outros humanos; não porque tenhamos experimentado o mesmo que eles, mas porque os descobrimos pelo registro em livros, textos ou tantas outras formas de linguagem. É por esse motivo que estudamos; não para meramente memorizarmos e, mais à frente, sermos testados por avaliações que esquadrinham um texto ou pensamento até transformá-lo em uma fórmula pasteurizada em que o percurso do autor pouco importa. Ao contrário, estudamos para nos inserir na humanidade.

Assim, tudo que é humano, tudo o que é experimentado pela humanidade, interessa à educação, desde que siga essa lógica do encontro, palavra central na concepção educacional de Papa Francisco.

Isso coloca em xeque a busca por padrões de comportamento, já que a experiência humana é dinâmica, não definida por padrões. Da mesma maneira, os conceitos de habilidades e competências, por essa vertente, são relativizados. As questões decorrentes são: competência para quê? Definida por quem? 
Os conceitos de competência e habilidade, embora já existentes na literatura educacional desde os anos 1950, ganharam projeção no Brasil nos anos 1990, a partir da demanda industrial decorrente de outro conceito da área gerencial: o de empregabilidade. Buscava-se, naquela quadra de nossa história, sugerir que o emprego estaria vinculado a novas exigências tecnológicas e organizacionais do mundo do trabalho que seriam a porta de entrada para o emprego contemporâneo. Muitos estudos adiante revelaram que o emprego não tinha relação direta com esse repertório de conteúdos educacionais: os setores que mais empregavam já no final dos anos 1990 não exigiam tantos requisitos, como no caso do comércio varejista. Contudo, o princípio se alojou como verdade pedagógica.

Para Perrenoud (1999), um dos autores mais citados nos debates educacionais brasileiros no início deste século XXI, competência é a capacidade de agir com eficácia em determinado tipo de situação prática da vida cotidiana. Para isso, é preciso lançar mão de conhecimentos e colocar em ação vários outros recursos cognitivos.

Já para Benno Sander (apud DAVOK, 2007), aos critérios clássicos de eficácia e eficiência na educação se agregaram, nos últimos anos, os critérios de efetividade e relevância cultural para elaboração de políticas públicas educacionais, relativizando ainda mais as noções de competência e habilidade como eixos educacionais. Vejamos a síntese realizada por Davok (2007, p. 510-511) a respeito dessa contribuição de Sander:

A eficiência "[...] é o critério econômico que revela a capacidade administrativa de produzir o máximo de resultados com o mínimo de recursos, energia e tempo" (p. 43). É um critério de dimensões instrumental e extrínseca. A eficácia “[...] é o critério institucional que revela a capacidade administrativa para alcançar as metas estabelecidas ou os resultados propostos" (p. 46). Esse critério é de dimensão instrumental e preocupa-se com a consecução dos objetivos intrínsecos, vinculados, especificamente, aos aspectos pedagógicos da educação. A efetividade "[...] é o critério político que reflete a capacidade administrativa para satisfazer as demandas concretas feitas pela comunidade externa" (p. 47). É um critério substantivo extrínseco que reflete a capacidade de a educação responder às preocupações, exigências e necessidades da sociedade. A relevância, por sua vez, "[...] é o critério cultural que mede o desempenho administrativo em termos de importância, significação, pertinência e valor" (p. 50). Esse critério é de natureza substantiva e intrínseca e está diretamente relacionado à atuação da educação para a melhoria do desenvolvimento humano e qualidade de vida dos indivíduos e grupos que participam do sistema educacional e da comunidade como um todo.

Esses quatro critérios não são excludentes na gestão da educação, porquanto, se complementam. Segundo Sander (1995, p. 67), “[...] 
embora distinguíveis, são dimensões dialeticamente articuladas de um paradigma abrangente e superador de administração da educação. No paradigma multidimensional de administração da educação a eficiência é subsumida pela eficácia; a eficácia e a eficiência são subsumidas pela efetividade; a efetividade, a eficácia e a eficiência são subsumidas pela relevância".

Como se percebe, a proposição de Sander indica a ausência de diálogo social do critério solitário de eficácia (sendo um critério institucional, enfocado na formulação do autor da política educacional). Efetividade e relevância cultural, ao contrário, são destacados como critérios eminentemente dialogais em conexão com demandas e interesses da comunidade externa ao ator institucional, gestor da política.

Assim, se, como sugere Perrenoud, as competências são capacidades para agir com eficácia a partir de uma situação prática, estamos diante de um instrumento de ação, não de um conhecimento. Tal instrumento faz uso de conhecimentos, mobiliza-os para se atingir uma meta, um resultado esperado, um objetivo. A questão não resolvida, contudo, é se a meta ou o objetivo definido é adequado. No entanto, o conceito de competência não reflete o mérito do objetivo escolhido, e sim o naturaliza como correto.

Em outras palavras, a competência a ser desenvolvida em um currículo é apresentada como um dado infalível, como um padrão a ser perseguido pelo processo educacional. Ora, para fugirmos dessa noção estandardizada de competência, temos de fugir da noção de padrão preestabelecido, caminhando para uma necessidade intelectual a partir de um problema que se apresenta ao educando.

Essa digressão sobre competências e habilidades se relaciona diretamente com a sugestão do Pacto Educativo Global, como veremos mais adiante, justamente porque competência não se confunde com aquisição escolar verificável, pois se relacionaria com resoluções de situações-problema; tampouco tem o mesmo significado de desempenho. Competências não são potencialidades humanas inatas; competências, portanto, são construídas, são aquisições. Construir uma competência é aprender a identificar e buscar os conhecimentos necessários para resolver uma situação-problema que surge em uma sociedade dinâmica, em movimento. A construção de competências está estreitamente vinculada à formação de esquemas de mobilização dos conhecimentos. Essa construção acontece em um contexto de ação, no âmbito da prática. Os sujeitos não constroem esquemas a partir de intervenções externas ou da interiorização de um procedimento (aulas expositivas ou demonstrativas, por exemplo). Esquemas se constroem a partir de um exercício do fazer, de experiências renovadas, que são mais eficazes por se associarem a uma postura reflexiva. Isso significa que, além de viver as experiências, os indivíduos deverão analisá-las. 
A concepção de currículo a partir dessa interpretação não é estática ou prescritiva, mas um currículo em ação.

Este é o desafio pedagógico central da educação proposta pelo Pacto Educativo Global: o diálogo com o mundo real, seus desafios e com o processo de escuta e mobilização de conhecimentos voltados para a ação coletiva.

A formação por situação-problema, que dialoga com o mundo vivido e sentido, aproxima a sala de aula dos desafios da sobrevivência e da busca de felicidade e comunhão. É uma educação que se relaciona com a vida cotidiana, que se apresenta como método para o diálogo, para a escuta e busca de superações.

É aqui que se articula o Pacto Educativo Global com a Economia de Francisco e Clara: pelo cuidado com o outro e com a Casa Comum; pela contextualização de todo o processo educativo no interior dessa Casa Comum, não como algo externo, que se apresenta como demiurgo, mas como relação refletida, pensada, comprometida.

E é aqui que nasce seu vínculo com o que alguns autores denominaram cidadania ativa: a cidadania que não se limita ao voto, mas avança para a corresponsabilidade na gestão das coisas públicas, na cogestão dos territórios e comunidades.

\section{As formulações do Papa Francisco a respeito dos desafios educacio- nais na direção do Pacto Educativo Global}

Em 12 de setembro de 2019, Papa Francisco emitiu uma mensagem convocando lideranças mundiais para o que denominou Pacto Educativo Global. Sabe-se que esse chamado nasceu de uma demanda inicial que lideranças muçulmanas e judias apresentaram ao Papa, o que já se reveste, logo de início, em um pacto ecumênico, fundado na fé, e também em um sentido de urgência que parece nos guiar neste início de século XXI.

Nessa mensagem, reafirmou o necessário cuidado com a "nossa casa comum", repetindo o alerta da Carta Encíclica Laudato Si'. O cuidado, afirma, será feito a partir de uma "nova solidariedade universal e uma sociedade mais acolhedora" (SAYAGO, 2019, p. 143). O pacto sugerido teria como elementos constitutivos "uma educação mais aberta e inclusiva, capaz de escuta paciente, diálogo construtivo e mútua compreensão" (SAYAGO, 2019, p. 143).

O pacto se fundamenta em um breve diagnóstico que o Papa Francisco (2019a, s/p) apresenta em sua mensagem de lançamento:

A educação é colocada à prova pela rápida aceleração que prende a existência no turbilhão da velocidade tecnológica e digital, mudando continuamente os pontos de referência. Neste contexto, perde consistência a própria identidade e desintegra-se a estrutura psicológica perante uma mudança incessante que "contrasta com a lentidão natural da evolução biológica”. 
Ressalta a necessidade de superação da fragmentação contemporânea. Sugere que "toda a mudança precisa duma caminhada educativa que envolva a todos" e, para tanto, sugere a construção de uma "aldeia da educação", na qual, na diversidade, partilhe-se o compromisso de gerar uma rede de relações humanas e abertas (FRANCISCO, 2019a, s/p). Trata-se de uma aliança mundial, "entre o estudo e a vida; entre as gerações; entre os professores, os alunos, as famílias e a sociedade civil, com as suas expressões intelectuais, científicas, artísticas, desportivas, políticas, empresariais e solidárias" (FRANCISCO, 2019a, s/p).

Desde 2013, Papa Francisco apresentou inúmeras reflexões a respeito dos desafios educacionais contemporâneos. O Pacto Educativo Global está assentado em um longo percurso reflexivo.

Vejamos alguns desses pensamentos e seu encadeamento. Desde o início de seu papado, o Papa Francisco foi muito objetivo nos desafios educacionais do mundo contemporâneo. Educação, aliás, mereceu atenção especial desde seus primeiros pronunciamentos.

Em 21 de novembro de 2015, na Sala Paulo VI do Vaticano, em discurso proferido no congresso mundial promovido pela Congregação para a Educação Católica, Papa Francisco recordou um conselho que deu às irmãs da Patagônia:

A uma congregação de irmãs com uma vocação especial na Argentina, para o Sul da Argentina, para a Patagônia, eu disse: por favor, fechar metade dos colégios da capital, de Buenos Aires, e enviai para lá as irmãs, para aquela periferia da pátria porque de lá virão as novas contribuições, os novos valores, e virão também as pessoas capazes de renovar o mundo (FRANCISCO, 2015d, s/p).

O conselho se embasava em uma leitura da realidade social que provoca o compromisso educacional, em especial, cristão. Nessa fala no congresso de novembro, Papa Francisco sustenta que o primeiro desafio educacional cristão seria deixar os lugares onde há muitos educadores e ir às periferias para procurar ali os que têm a experiência da sobrevivência, da fome, das injustiças, que têm a humanidade ferida. Nas suas palavras:

Eles têm uma coisa que os jovens dos bairros mais ricos não possuem - não por culpa deles, mas porque é uma realidade sociológica: têm a experiência da sobrevivência, também da crueldade, da fome, das injustiças. Têm uma humanidade ferida. E penso que a nossa salvação vem das feridas de um homem ferido na cruz. Daquelas feridas, eles obtêm sabedoria, se houver um bom educador que os leve em frente. Não se trata de ir lá fazer beneficência, ensinar a ler, dar de comer... não! Isto é necessário, mas é provisório. É o primeiro passo. O desafio - e eu os encorajo - é ir lá para os fazer crescer em humanidade, em inteligência, em valores, em hábitos, para que possam ir em frente e levar aos outros experiências que não conhecem (FRANCISCO, 2015d, s/p). 
Ainda nessa oportunidade, Papa Francisco avança sobre a urgência de um pacto educativo que adote como referência a superação do neopositivismo, que só educa para as coisas imanentes e se esquece da transcendência. Sugere que não se pode falar em Educação Católica sem falar de humanidade. Sustenta que educar é conduzir jovens e crianças nos valores humanos em todas as realidades:

Hoje há a tendência a um neopositivismo, ou seja, a educar para as coisas imanentes, para o valor das coisas imanentes, e isto tanto nos países de tradição cristã como nos países de tradição pagã. $\mathrm{O}$ que não significa introduzir os jovens, as crianças na realidade total: falta a transcendência. [...] A educação tornou-se demasiada seletiva e elitista. Parece que só os povos e as pessoas com um certo nível ou capacidade têm direito à educação; mas sem dúvida nem todas as crianças e jovens têm direito à educação. Esta é uma realidade mundial que nos envergonha. É uma realidade que nos leva a uma seletividade humana, e que em vez de aproximar os povos, afasta-os. [...] Mas isto acontece também em nosso âmbito: o pacto educativo entre a família e a escola se quebrou! Deve-se recomeçar. [...] A educação formal empobreceu por causa da herança do positivismo. Concebe apenas um tecnicismo intelectualista e a linguagem da mente. E por isso empobreceu-se. É preciso interromper este esquema. E há experiências como a arte, o esporte. A arte e o esporte educam. É preciso abrir-se a novos horizontes, criar novos modelos (FRANCISCO, 2015d, s/p).

Essa passagem indica nitidamente uma revisão das prioridades educacionais para crianças e jovens. Um currículo aberto, que supere as hierarquias de conteúdos enfocada na inserção no mundo de racionalidades e sucessos individuais. Não foi a primeira vez que Papa Francisco sugeriu o abandono da área de conforto na prática educacional. Em 2013, já havia fundamentado essa necessidade a partir de um esforço de empatia com a busca dos jovens. Em 7 de junho daquele ano, ao responder às perguntas dos representantes das escolas dos jesuítas na Itália e na Albânia, sustentou que era necessário que todos fossem magnânimos, sem medo, apostando sempre em grandes ideais. E propõe:

Na educação, há um equilíbrio a respeitar, há que equilibrar bem os passos: um passo firme na zona de segurança, mas o outro entrando na área de risco. E quando este risco se torna segurança, o passo seguinte procura outra zona de risco (FRANCISCO, 2013a, s/p).

Mas, afinal, por que o risco, enquanto ato pedagógico? Papa Francisco, em um outro encontro, realizado em 21 de agosto de 2013, ao falar para professores do colégio japonês Seibu Gakuen Bunri Junior High School de Saitama, explicita sua leitura sobre o movimento de encontro aos jovens. Esse movimento é uma 
das chaves de suas reflexões educacionais: a pedagogia do encontro. Para o Papa, ao nos isolarmos em nós mesmos, só teremos o que já temos e não cresceremos culturalmente. O diálogo, então, torna-se um exercício de amadurecimento, no confronto de culturas, de experiências humanas. E sustenta:

E qual é a atitude mais profunda que devemos ter para dialogar e não brigar? A mansidão, a capacidade de encontrar as pessoas, de encontrar as culturas com a paz; a capacidade de fazer perguntas inteligentes: "mas por que pensas assim? Por que esta cultura é assim?" Ouvir o próximo e depois falar. Primeiro ouvir, depois falar (FRANCISCO, 2013b, s/p).

E, na escuta, revela-se o lugar do professor "incompleto": “[...] os jovens compreendem, 'farejam' e são atraídos pelos professores que têm um pensamento aberto, 'incompleto', que procuram 'um mais', e assim contagiam os estudantes com esta atitude" (FRANCISCO, 2014c, s/p).

Uma pedagogia aberta, dinâmica, da escuta e do encontro de experiências e culturas.

Assim, a escola apresenta-se como espaço de abertura à realidade e um lugar de encontro. E é a partir dessa escola - e de todo o processo educacional - como espaço de encontro que Papa Francisco esboça a aldeia educacional. Nesse encontro com as escolas católicas, em 2014, cita um provérbio africano que diz "para educar uma criança é necessária uma aldeia", uma ação conjunta, contributiva, de várias experiências e esforços. "Para educar um jovem", afirma, "é necessária muita gente: família, professores da escola básica, pessoal não docente, professores, todos!”. E, ainda: “amo a escola porque nos educa para o verdadeiro, para o bem e o belo. Os três caminham juntos. A educação não pode ser neutra. Ou é positiva ou negativa; ou enriquece ou empobrece" (FRANCISCO, 2014c, s/p).

E, então, em 4 de setembro de 2014, o Pacto Educativo Global parece se esboçar mais nitidamente. Em um discurso realizado no encontro mundial dos diretores de Scholas Ocurrentes, Papa Francisco sugere a recomposição do pacto educativo, recomposição daquela aldeia para educar crianças:

Não podemos deixá-las sozinhas, não podemos deixá-las pelas ruas, sem tutela, à mercê do mundo, no qual prevalece o culto do dinheiro, da violência e do descartável. Insisto muito sobre este tema, mas é evidente que se impôs a cultura do descartável. O que não serve joga-se fora. Descartam-se os jovens porque não os educamos ou não queremos educá-los (FRANCISCO, 2014d, s/p).

No encontro seguinte das Scholas Ocurrentes, realizado em 5 de fevereiro de 2015, complementa: 
É o pacto educacional, um pacto educativo que se cria entre a família, a escola, a pátria, a cultura. Rompeu-se profundamente e já não se consegue consertar. $\mathrm{O}$ pacto educacional que se rompeu significa que tanto a sociedade como a família e as diversas instituições delegam a educação aos agentes da educação, aos docentes que - geralmente mal pagos - carregam nos seus ombros esta responsabilidade e, se não obtêm bons resultados, são repreendidos. Mas ninguém recrimina as várias instituições, que faltaram ao pacto educativo, delegando-o ao profissionalismo de um professor. [...] Scholas deseja harmonizar a linguagem da cabeça com a linguagem do coração e das mãos. Que uma pessoa, uma criança, um jovem pense no que sente e faz; que sinta aquilo em que pensa e o que faz; que faça o que sente e aquilo em que pensa (FRANCISCO, 2015a, s/p).

Papa Francisco (2015a, s/p) sustenta a necessidade de se descobrir o jogo como caminho educacional, já que a educação "não é apenas informação, mas criatividade no jogo, aquela dimensão lúdica que nos faz crescer na criatividade e no trabalho em equipe",

A concepção educacional sugerida pelo Papa apoia-se, assim, em vários aspectos:

1. O valor do diálogo, que fundamenta o pluralismo cultural e religioso.

2. A preparação qualificada de formadores, tendo em mente que não podem improvisar e que educar é um ato de amor exigente,

muito competente, qualificado e, ao mesmo tempo, rico de humanidade, capaz de permanecer no meio dos jovens com um estilo pedagógico, para promover o seu crescimento humano e espiritual. [...] Não se pode educar sem coerência e testemunho (FRANCISCO, 2014a, s/p).

3. A integração ao mundo, evitando-se o isolamento. É preciso que se saiba "entrar intrepidamente no areópago das culturas contemporâneas e estabelecer um diálogo, conscientes do dom que podem oferecer a todos" (FRANCISCO, 2014a, s/p).

4. Transmitir conteúdos, hábitos e sentidos dos valores, os três elementos juntos (FRANCISCO, 2014).

5. Falar nas três línguas: a língua da mente, a língua do coração e a língua das mãos.

6. A educação do cuidado com a Casa Comum, para a educação e espiritualidade ecológicas (FRANCISCO, 2015b).

Essa é a estrutura de pensamento e do projeto educacional de Papa Francisco que se plasmou no Pacto Educativo Global; projeto que se revela mais intensamente em uma reflexão que fez em 7 de julho de 2015, em Quito, na Pontifícia Universidade Católica do Equador: 
Eu vivo em Roma. No inverno, faz frio. Pode acontecer que, bem pertinho do Vaticano, apareça um idoso, pela manhã, que morreu por causa do frio. Não é notícia em nenhum dos jornais, em nenhum relato. Um pobre morre por causa do frio e da fome e isso não é notícia, mas se as bolsas das principais capitais do mundo caem dois ou três pontos arma-se um grande escândalo mundial. Eu me pergunto: onde está o teu irmão? E peço-vos que vos façais outra vez, cada um, essa pergunta, e que o façais à universidade: A ti, Universidade Católica, onde está o teu irmão? (FRANCISCO, 2015c, s/p).

O Pacto Educativo e o encontro pela Economia de Francisco compõem esse tecido que vem envolvendo inúmeras práticas, discussões, reflexões em torno de um novo humanismo. Ancorado nas dimensões da proximidade, da partilha, da solidariedade, é um despertar para novas práticas. Mais do que um pacto de governo, dimensiona uma política de sociedade, que retoma as relações comunitárias como capazes de perfazer os cenários que compõem a visão e a prática nas instituições democráticas, a saber, a Igreja Católica, os movimentos sociais, as universidades e o Estado.

"Realmar" a economia se assemelha a buscar a humanização, porém, desta vez, biocêntrica, prevalecendo o todo da dimensão da vida do planeta em complementaridade à vida humana. Essa dimensão avança sobre novas perspectivas teológicas, políticas, econômicas e culturais a se desenharem nos marcos desses dois pactos e também na dinâmica das comunidades, territórios e povos que ensaiam resistência e lutas pela mudança radical dessa sociedade que aqui está.

Submissão: $25 / 03 / 2020$

Revisão: 20/04/2020

Aprovação: 25/04/2020

\section{Notas}

1 Educador e sociólogo, atua com movimentos populares e religiosos na Zona Leste de São Paulo. É consultor do Instituto Cultiva. Faz parte da Coordenação da ABEFC - Articulação Brasileira pela Economia de Francisco e Clara. E-mail: eduardobrasileiroc@gmail.com

2 Sociólogo, mestre e doutor em Ciências Sociais pela Universidade Estadual de Campinas (UNICAMP). Assessor de movimentos populares e sindicais no Brasil. É presidente do Instituto Cultiva e membro da Coordenação da ABEFC - Articulação Brasileira pela Economia de Francisco e Clara, e também da Articulação Brasileira pelo Pacto Educativo Global.

\section{Referências}

ACOSTA, Alberto. O Bem Viver: uma oportunidade para imaginar outros mundos. São Paulo: Autonomia Literária, 2016. 
ARENDT, Hannah. A condição humana. 11 ed. Rio de Janeiro: Forense Universitária, 2010.

ARTICULAÇÃO BRASILEIRA PELA ECONOMIA DE FRANCISCO E CLARA. Carta de Clara e Francisco. Direto do Brasil para o Encontro Mundial em Assis. Instituto Humanitas Unisinos, 30 nov. 2019. Disponível em: http://www.ihu.unisinos.br/78-noticias/594766-carta-de-clara-e-francisco-direto-do-brasil-para-o-encontro-mundial-em-assis. Acesso em: 19 dez. 2019

DARDOT, Pierre; LAVAL, Christian. A nova razão do mundo: ensaio sobre a sociedade neoliberal. São Paulo: Boitempo, 2016.

DAVOK, Delsi Fries. Qualidade em educação. Avaliação, Campinas, v. 12, n. 3, p. 505-513, set. 2007. Disponível em: http://www.scielo.br/scielo.php?scrip$\mathrm{t}=$ sci_arttext\&pid=S1414-40772007000300007. Acesso em: 7 dez. 2019.

DILGER, Gerhard; LANG, Miram; PEREIRA FILHO, Jorge (org.). Descolonizar o imaginário. São Paulo: Fundação Rosa Luxemburgo, 2016.

DURKHEIM, Emile. Educação e sociologia. São Paulo: Edições Melhoramentos, 1975.

FRANCISCO, Papa. Respostas às perguntas dos representantes das escolas dos jesuítas na Itália e na Albânia. Vaticano, 7 jun. 2013a. Disponível em: http://www.vatican.va/content/francesco/pt/speeches/2013/june/documents/ papa-francesco_20130607_scuole-gesuiti.html. Acesso em: 12 dez. 2019.

FRANCISCO, Papa. Discurso aos estudantes e aos professores do colégio japonês Seibu Gakuen Bunri Junior High School de Saitama - Tóquio. Vaticano, 21 ago. 2013b. Disponível em: http://www.vatican.va/content/francesco/pt/speeches/2013/august/documents/papa-francesco_20130821_collegio-saitama-giappone.pdf. Acesso em: 12 dez. 2019.

FRANCISCO, Papa. Exortação Apostólica Evangeli Gaudium: o anúncio do Evangelho no mundo atual. Roma, 24 nov. 2013c. Disponível em: http:/ / www.vatican.va/content/francesco/pt/apost_exhortations/documents/papa-francesco_esortazione-ap_20131124_evangelii-gaudium.html. Acesso em: 12 dez. 2019.

FRANCISCO, Papa. Discurso aos participantes na plenária da Congregação para a Educação Católica. Vaticano, 14 fev. 2014a. Disponível em: http://www.vatican.va/content/francesco/pt/speeches/2014/february/documents/papa-francesco_20140213_congregazione-educazione-cattolica.html. Acesso em: 7 dez. 2019.

FRANCISCO, Papa. Discurso à plenária da Pontifícia Comissão para a América Latina. Vaticano, 28 fev. 2014b. Disponível em: http:/ /www.vatican. 
$\mathrm{va} /$ content/francesco/pt/speeches/2014/february/documents/papa-francesco_20140228_pontificia-commissione-america-latina.html. Acesso em: 7 dez. 2019.

FRANCISCO, Papa. Discurso aos estudantes e professores das escolas italianas. Vaticano, 10 maio 2014c. Disponível em: http://www.vatican. $\mathrm{va} /$ content/francesco/pt/speeches/2014/may/documents/papa-francesco_20140510_mondo-della-scuola.html. Acesso em: 7 dez. 2019.

FRANCISCO, Papa. Discurso aos participantes do Encontro Mundial dos Directores de "Scholas Occurrentes". Vaticano, 4 set. 2014d. Disponível em: http://w2.vatican.va/content/francesco/pt/speeches/2014/september/ documents/papa-francesco_20140904_direttori-scholas-occurrentes.html. Acesso em: 7 dez. 2019.

FRANCISCO, Papa. Discurso por ocasião do IV Congresso Mundial de “Scholas Occurrentes". Vaticano, 5 fev. 2015a. Disponível em: http://www. vatican.va/content/francesco/pt/speeches/2015/february/documents/papa-francesco_20150205_scholas-occurrentes.html. Acesso em: 7 dez. 2019.

FRANCISCO, Papa. Laudato Si': sobre o cuidado da Casa Comum. Roma, 24 maio 2015b. Disponível em: http://w2.vatican.va/content/francesco/pt/encyclicals/documents/papa-francesco_20150524_enciclica-laudato-si.html. Acesso em: 7 dez. 2019.

FRANCISCO, Papa. Encontro com o mundo da escola e universidade: discurso do Santo Padre. Quito, 7 jul. 2015c. Disponível em: http://www. vatican.va/content/francesco/pt/speeches/2015/july/documents/papa-francesco_20150707_ecuador-scuola-universita.html. Acesso em: 7 dez. 2019.

FRANCISCO, Papa. Discurso aos participantes no congresso mundial promovido pela Congregação para a Educação Católica com o tema: "Educar hoje e amanhã. Uma paixão que se renova". Vaticano, 21 nov. 2015d. Disponível em: http://www.vatican.va/content/francesco/pt/speeches/2015/ november/documents/papa-francesco_20151121_congresso-educazione-cattolica.html. Acesso em: 7 dez. 2019.

FRANCISCO, Papa. Mensagem para o lançamento do pacto educativo. Vaticano, 12 set. 2019a. Disponível em: http://w2.vatican.va/content/francesco/pt/messages/pont-messages/2019/documents/papa-francesco_20190912_ messaggio-patto-educativo.html. Acesso em: 12 dez. 2019.

FRANCISCO, Papa. Carta para o evento "Economy of Francesco". Vaticano, $1^{\circ}$ maio 2019b. Disponível em: http:/ /www.vatican.va/content/francesco/ pt/letters/2019/documents/papa-francesco_20190501_giovani-imprenditori. html. Acesso em: 12 dez. 2019. 
FREIRE, Paulo. Pedagogia da autonomia: saberes necessários à prática educativa. São Paulo: Paz e Terra, 1996.

IANNI, Octavio. A Política mudou de Lugar. São Paulo em Perspectiva, v. 11, n. 3, p. 3-7, 1997. Disponível em: http://produtos.seade.gov.br/produtos/ spp/v11n03/v11n03_01.pdf. Acesso em: 11 dez. 2019.

LATOUR, Bruno. Políticas da natureza: como associar as ciências à democracia. São Paulo: UNESP, 2019

LA VANGUARDIA. Papa Francisco e Joseph Stiglitz querem estimular uma "economia social de mercado" que dê voz aos jovens. Barcelona, 13 maio 2019. Disponível em: http:/ /www.ihu.unisinos.br/78-noticias/ 589135-papa-francisco-e-joseph-stiglitz-querem-estimular-uma-economia-social-de-mercado-que-de-voz-aos-jovens. Acesso em: 12 dez. 2019.

LÉVI-STRAUSS, Claude. Antropologia estrutural dois. São Paulo: Cosac Naify, 2013.

MBEMBE, Achille. Necropolítica. São Paulo: N-1 Edições, 2018.

MORIN, Edgard. Ciência com consciência. Rio de Janeiro: Bertrand, 2000.

PERRENOUD, Philippe. Construir as competências desde a escola. Porto Alegre: Artes Médicas, 1999.

RAVITCH, Diane. Vida e morte do grande sistema escolar americano: como os testes padronizados e o modelo de mercado ameaçam a educação. Porto Alegre: Sulina, 2011.

SANTOS, Boaventura de Sousa. Um discurso sobre as ciências. 16. ed. Porto: Edições Afrontamento, 2010.

SAYAGO, Óscar Armando Perez (org.). O projeto educativo de Francisco. Curitiba: Pucpress, 2019

STREECK, Wolfgang. Tempo comprado: a crise adiada do capitalismo democrático. São Paulo: Boitempo, 2012. 